\title{
Experimental and numerical study on power consumptions in a double-tube-socket pneumatic conveying system
}

\author{
Chun-xia Zhang a, Yu Zhang ${ }^{\mathrm{b}, *}$, Don McGlinchey ${ }^{\mathrm{c}}$, Yan Du ${ }^{\mathrm{a}}$, Xiaolin Wei ${ }^{\mathrm{b}}$, Lv-ao Ma ${ }^{\mathrm{a}}$, Chun-sheng Guan ${ }^{\mathrm{a}}$ \\ a China Electric Power Research Institute, Beijing 100055, China \\ ${ }^{\mathrm{b}}$ Institute of Mechanics, Chinese Academy of Sciences, Beijing 100190, China \\ c School of Engineering and Computing, Glasgow Caledonian University, UK
}

\section{A R T I C L E I N F O}

\section{Article history:}

Received 21 April 2010

Received in revised form 28 July 2010

Accepted 1 August 2010

Available online 13 August 2010

\section{Keywords:}

Pneumatic conveying

DTS

Power consumption

\begin{abstract}
A B S T R A C T
A new methodology is proposed in this paper to predict the lowest power consumption for a double-tubesocket (DTS) pneumatic conveying system. This methodology is established on both experimental work and numerical simulation. After parametric studies by numerical simulation, the desired conveying cases which have the lowest power consumption were obtained. Finally those cases were carried out in our experimental system. The measured power consumption was close to that predicted. In this paper the experimental work is discussed and the numerical simulation introduced.
\end{abstract}

(c) 2010 Elsevier B.V. All rights reserved.

\section{Introduction}

Pneumatic conveying systems are mechanically simple and suitable for the transport of powdered and granular materials in factory, site and plant situations. The systems include a source of carrier gas, a feeding device, a conveying pipeline, and a receiver to separate the conveyed material and the carrier gas. The systems are totally enclosed and a range of pressures, whether high, low or negative can be used to convey materials [1].

Pneumatic conveying has become more popular in recent years, particularly dense phase systems, due to their relative low power consumption and a clean working environment. However, when conveying in dense phase a blockage can occur due to an overly thick layer of conveyed material [2]. Consequently, the use of a bypass line is proposed so that air flow in the bypass can mitigate the formation of a thick layer of material in the main conveying pipe [2,3]. The technique of using a bypass placed inside the main pipeline has been around since 1980 [1], and this technique is referred to as the doubletube-socket (DTS) in this paper.

The DTS conveying system employs a small pipe running inside the conveying line, having fixed openings at regular intervals along its length. The cross sectional area of the inner pipe is typically $20-25 \%$ of the total cross section of the main pipeline. The space of the openings of the internal pipe depends on the permeability and de-aeration of the conveyed material. These parallel pipes are not supplied with an external supply of air, but air within the conveying line can enter freely

\footnotetext{
* Corresponding author. Tel.: +8610 82544231; fax: +861062561284 E-mail address: zhangyu@imech.ac.cn (Y. Zhang).
}

through the regular openings provided. The inner bypass is generally confined to straight horizontal lengths of the conveying pipeline only, but not the bends or vertical sections.

DTS conveying systems are generally employed for materials that are relatively impermeable to air and which tend to form plugs in the main pipeline when conveyed at a low velocity. The plugs may occupy the full cross section of the pipeline in the worst case. If the material presents a high resistance, the air will be forced to flow through the bypass pipe. As the bypass pipe is much smaller in diameter than the conveying pipeline, the air will be forced back into the pipeline through subsequent downstream openings as the resistance in the main line reduces, and this will affect a break-up of the plug of the material causing the blockage. A long plug of the material is thus divided up into short slugs that are readily conveyed. Fig. 1 shows a snapshot that was observed during DTS conveying. It gives the direct physical sense of how DTS works.

Until now, the details of the DTS conveying mechanism were not fully understood, and all parameters of the DTS system, such as pressure of the carrier gas, were designed empirically. A huge amount of test work would therefore be needed to find the lowest power consumption for conveying a given amount of material a set distance.

In recent years, $\mathrm{CFD}$ (Computational Fluid Dynamics) has become a very powerful tool for simulations of varied industrial complex flows in order to reduce the amount of experimental testing required. Many investigations have been reported on that use of CFD to analyze the pneumatic conveying process [4-8], and it involves many interesting topics such as the pressure drop, the roughness of the wall and a bend in the pipeline, etc. However, till now, due to the complexity of DTS conveying, there is no satisfactory CFD method for the prediction and minimization of the power consumption in DTS conveying. 


\begin{tabular}{|c|c|}
\hline \multicolumn{2}{|c|}{ Nomenclature } \\
\hline$m_{e}$ & the solids flow rate in the experiment, $\mathrm{t} / \mathrm{h}$; \\
\hline EO & $\begin{array}{l}\text { the power consumption per meter in the developed } \\
\text { part, } \mathrm{W} / \mathrm{m} \text {; }\end{array}$ \\
\hline E1 & the power consumption in the developing part, W; \\
\hline$e$ & the unit power consumption, $(\mathrm{kW} \mathrm{h}) /(\mathrm{t} \mathrm{km})$; \\
\hline$P$ & the conveying pressure, $\mathrm{Pa}$; \\
\hline Q & $\begin{array}{l}\text { the measured air flow rate at the outlet of the air } \\
\text { compressor, } \mathrm{Nm}^{3} / \mathrm{h} \text {; }\end{array}$ \\
\hline$L$ & the length of whole pipeline, $\mathrm{m}$; \\
\hline LO & the length of the developed section, m; \\
\hline L1 & the length of the developing section, m; \\
\hline E & the total power consumption, $\mathrm{W}$; \\
\hline
\end{tabular}

This study investigated the DTS conveying system by experiment and by mathematical modeling. In the experiment work, the conveying air pressure and air volumetric flow rate can be separately controlled. An Euler-Euler model was used to simulate the system and to predict the movement of both carrier gas and conveyed material. Furthermore, based on CFD results a simple computational program was developed that outputs the lowest power consumption of conveying from the input of only the required mass flow rate and conveying distance. The predicted lowest power consumption [10] was in good agreement with the result from a verification experiment.

\section{Experimental}

The straight length of the experimental conveying pipeline was about $100 \mathrm{~m}$. Taking the equivalent distance of bends and vertical sections into account the whole pipeline reaches an equivalent length of $200 \mathrm{~m}$. The straight section contains an inner bypass line with openings. The regular interval size between two openings is $430 \mathrm{~mm}$. Each opening has two pitches, they are $40^{\circ}$ to upstream and $60^{\circ}$ to downstream. The diameter of the inner bypass pipe is $50 \mathrm{~mm}$ (see Fig. 1). The volumetric capacity of the feeding device is $4 \mathrm{~m}^{3}$. The maximum delivery pressure of the air compressor is $0.7 \mathrm{MPa}$. The main parameters of the experimental conveying system are shown in Table 1.

There is a series of pressure transmitters and flow meters placed along the pipeline in order to monitor the pressures and air volumetric flow rates during conveying. The solids flow rates are also recorded by a mass balance placed at the bottom of the feeding device. (see Fig. 2). The experimental data is recorded on-line per second $(1 \mathrm{~Hz})$.

The material conveyed in the pipeline was pulverized coal ash. The characteristics of the ash are showed in Table 2. The 'Uniformity parameter' is defined as a ratio of a diameter which represents $10 \%$ of all the particles to that diameter which represents $60 \%$ of all the particles. It can be seen that the diameters of the ash particles are
Table 1

The parameters of the experimental conveying system.

\begin{tabular}{lll}
\hline No. & Items & Parameter \\
\hline 1 & Straight pipeline length & $100 \mathrm{~m}$ \\
2 & Pipe diameter & $94 \mathrm{~mm}$ \\
3 & Feed device volume & $4 \mathrm{~m}^{3}$ \\
4 & Number of feed devices & 1 \\
5 & Number of air compressors & 1 \\
6 & Air compressor parameters & $0.7 \mathrm{Mpa}, 10 \mathrm{~m}^{3} / \mathrm{min}$ \\
7 & The receiver volume & $15 \mathrm{~m}^{3}$ \\
8 & Bends & $9 \times 90^{\circ}(\mathrm{d} / \mathrm{D}=8.0)$ \\
9 & Vertical (up) section & $10 \mathrm{~m}$ \\
10 & Number of pressure transmitters & 10 \\
11 & Number of flow meters & 5 \\
12 & Number of weight transmitters & 2 \\
\hline
\end{tabular}

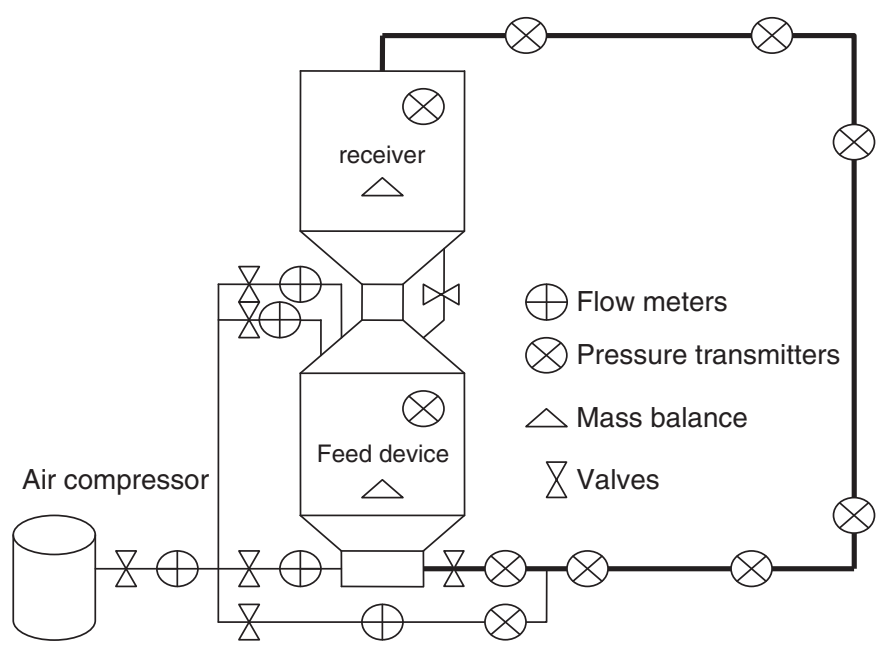

Fig. 2. The experimental DTS pneumatic conveying system.

rather uniform. According to the Geldart diagram [9], the pulverized coal ash belongs to the ' $A$ ' type group of materials, indicating that it is a potential candidate for dense phase conveying.

Initially the valve at the outlet of the feeding device was closed in order to pre-pressurise the system. When the pressure of the outlet of the feeding device rises to a certain value, such as $120 \mathrm{kPa}$, the valve was opened, thereupon the material entered the line and conveying started.

\section{Numerical simulation}

In industrial ash handling systems the conveying distance can reach kilometers. It would be impractical to simulate the whole conveying pipeline. It has been shown by experimental data (see Section 4) that the whole pipeline can be divided into (1) a developing section and (2) a fully developed section. In the developing section the

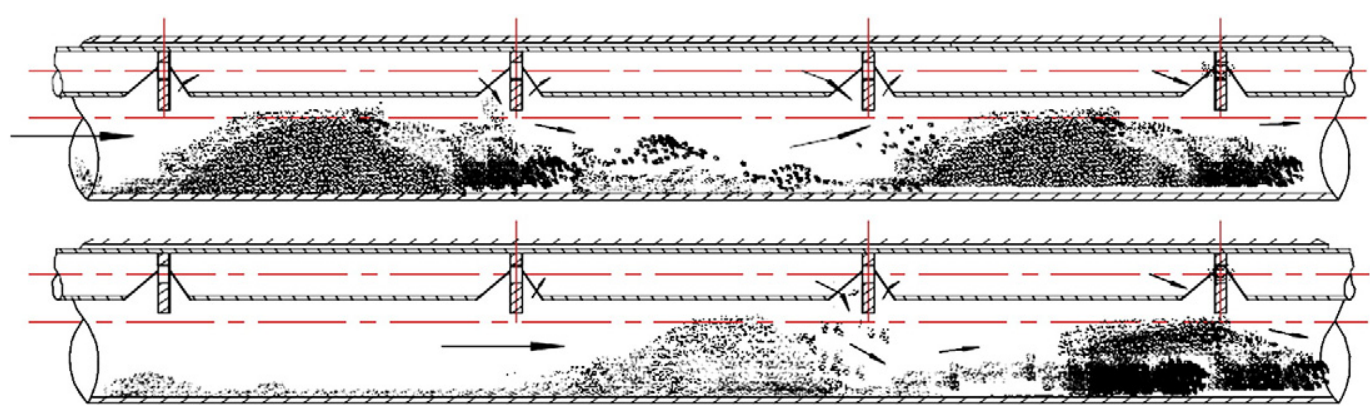

Fig. 1. The principle of the double-tube-system conveying pipe. 
Table 2

The characteristics of the material.

\begin{tabular}{|c|c|c|c|c|c|c|c|c|}
\hline Name & Pile angle & $\begin{array}{l}\text { Breakdown } \\
\text { angle }\end{array}$ & $\begin{array}{l}\text { Difference } \\
\text { angle }\end{array}$ & $\begin{array}{l}\text { Specific gravity } \\
\text { of pile }\end{array}$ & $\begin{array}{l}\text { Mean } \\
\text { diameter }\end{array}$ & $\begin{array}{l}\text { Uniformity } \\
\text { parameter }\end{array}$ & $\begin{array}{l}\text { Terminal settling } \\
\text { velocity }\end{array}$ & $\begin{array}{l}\text { Minimum fluidizing } \\
\text { velocity }\end{array}$ \\
\hline Pulverized coal ash & $54^{\circ}$ & $40^{\circ}$ & $14^{\circ}$ & 0.772 & $90 \mu \mathrm{m}$ & 11 & $0.147 \mathrm{~m} / \mathrm{s}$ & $0.06 \mathrm{~m} / \mathrm{s}$ \\
\hline
\end{tabular}

pressure gradient sharply decreases whereas in the developed section the pressure gradient is almost stable. Fig. 3 gives a series of simulated particle volume fractions in one part of the fully developed section at different times ( $t=0.37 \mathrm{~s}, 0.39 \mathrm{~s}, 0.40 \mathrm{~s})$. It can be seen that the flow pattern of particles is periodic due to the fact that the pressure gradient in that part is almost a constant.

Because of mass and momentum conservation, the velocity distributions of both air and particles at the outlet of the developing section must be the same as at the inlet of the developed section. A commercial software, FLUENT, combined with our own subroutines was employed for the simulation work. The simulation is unsteady and the time step is maximally $0.001 \mathrm{~s}$. The simulation is two-dimensional, and an area equivalent method was used for connection of the twodimensional simulation and the real three-dimensional system, which is illustrated in Fig. 4. Here, $\mathrm{H}$ is the thickness of the material layer, $\mathrm{R}$ is the radius of the pipeline, and $\mathrm{S}_{2}$ is the calculated three-dimensional equivalent area. Certainly, this area equivalent method is rough. But in practice it greatly saved computational time and gave relative reasonable results. 3-D calculations should be applied in the future, if powerful computers are not the problem, because 3-D calculation can fully avoid the area equivalent assumption.

In the developing section the air was compressible, whereas in the developed section the air was treated as incompressible because pressure gradients are small.
For the simulation of the developed part, the $2 \mathrm{D}$ arrangement of more than 20,000 grid cells was used. In order to make the periodic boundary conditions effective, the calculation domain must contain at least 4 interval nozzles (bypass line openings). The relaxation factors for solving the conservation equations were set at 0.5-0.8, dependent on the individual case. The calculation was 'unsteady' and the time step not greater than $0.001 \mathrm{~s}$ to achieve stable solutions. Therefore, although the simulation object is only $1.7 \mathrm{~m}$ long (containing 4 interval nozzles), on average, running one case until convergence took more than 20 days using a computer with core $22.0 \mathrm{GHz} \mathrm{CPU}$. For the simulation of the developing section, the simulation object was varied in length to guarantee that the flow pattern at its outlet reached the developed stage. All the other simulation details of the developing section remained the same as the developed section.

In undertaking the numerical simulation, firstly, the fully developed section was simulated. The possible pressure gradients according to the experimental results were set as periodic boundary conditions for CFD calculation. After running the simulation, the velocity profiles of both gas and particles in that section were obtained, so that the solids flow rate, air flow rate and power consumption of the fully developed part were also specified. Secondly, the obtained velocity profiles of the developed section were applied as the outlet boundary conditions for the developing section to do another CFD calculation. Consequently, the power consumption in the
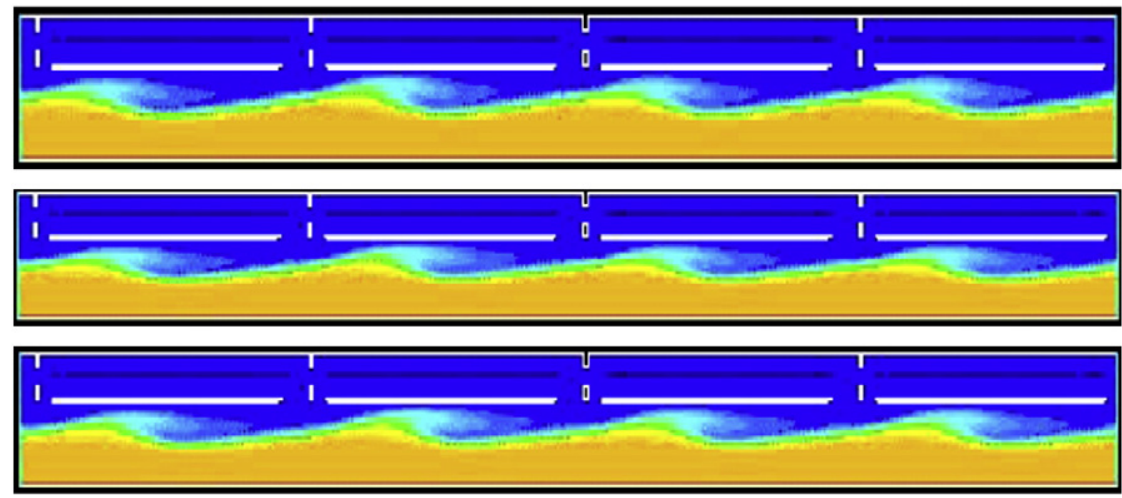

Fig. 3. A section of a tube with four hatches.

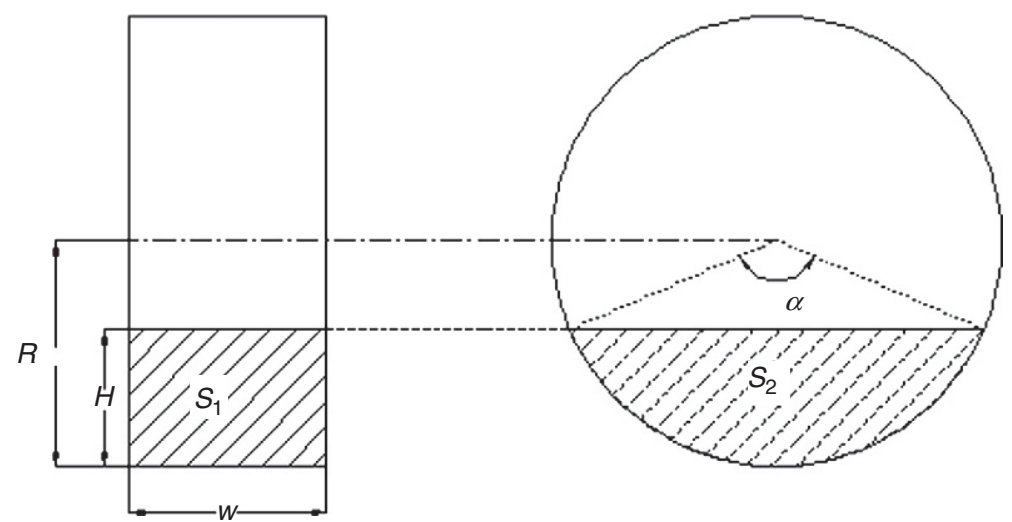

$\begin{array}{ll}\text { (a) The section of numerical 2D model } & \text { (b) The radial section of reality tube }\end{array}$

Fig. 4. The area equivalent method. 


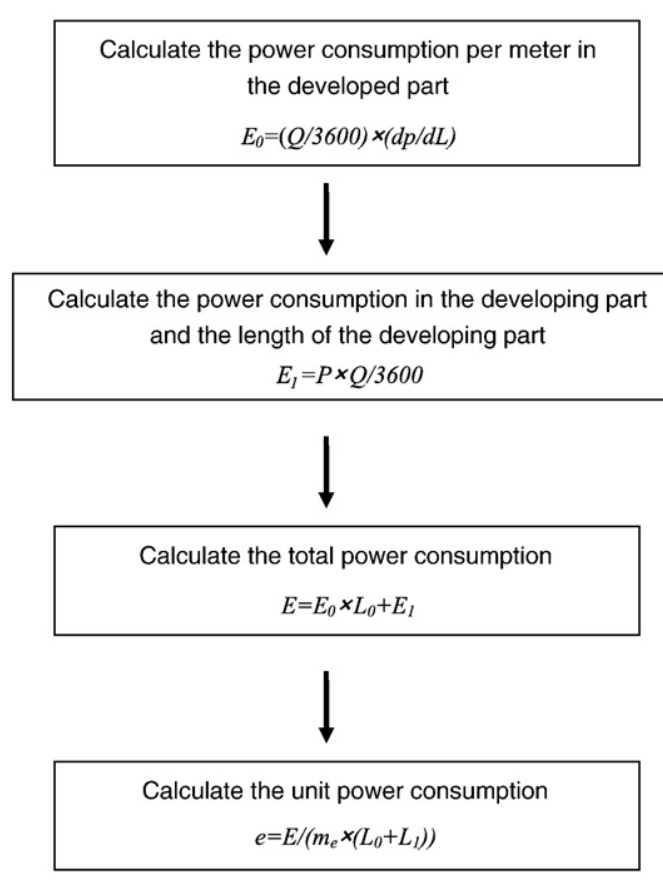

Fig. 5. The methodology to calculate power consumptions.

developing part was obtained. Adding the power consumptions of the developed section to that of the developing section, the total power consumption was obtained. The unit conveying power consumption comparable with the experimental measurement is defined as the total power consumption divided by solids flow rate and conveying distance. The whole methodology of calculation unit power consumption using CFD is illustrated in Fig. 5. The equations used were obtained from a technical report of a conveying company.

Taking the reasonable thicknesses of the material layer as initial calculation conditions, the unit power consumption can be obtained for all the cases. It should be noted that for a given solids flow rate, more than one case is feasible for conveying but only one of them has the lowest unit power consumption. And that case is the optimum one. It should be pointed out that all bends and vertical sections of the pipeline were converted to a 'straight section' by accounting their equivalent distance. Obviously, that is only a rough treatment, and needs future improvement. The whole methodology of simulation can be found in our previous publication [10].

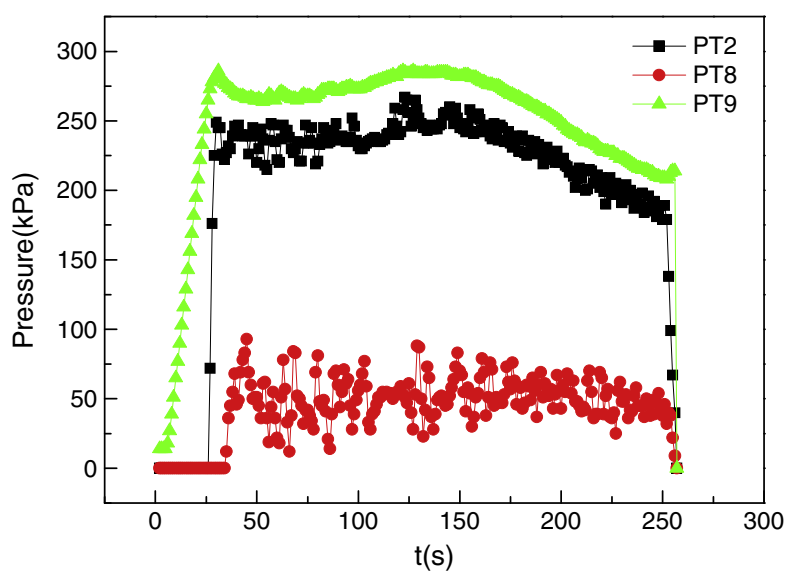

Fig. 6. Pressure history $\left(Q=1000 \mathrm{~m}^{3} / \mathrm{h}\right)$.

\section{Results and discussion}

\subsection{Experiment}

The pressure transmitter and the air volume flow meter record the data on-line. During the conveying process, the pressure histories inside the feed device (PT9) and at the outlet of the feed device (PT2) are shown in Fig. 6. (The pressure history in the developed region near the receiver is also shown (PT8)). Except in the initial and final transients, the pressures are almost constant.

Fig. 7 gives the pressure gradients obtained from measurements taken along the conveying line. In this case, the solids flow rate is $23.4 \mathrm{t} / \mathrm{h}$, air volumetric flow rate is $300 \mathrm{Nm}^{3} / \mathrm{h}$, and the conveying air pressure is $440 \mathrm{kPa}$. There were 9 pressure transmitters placed along the conveying pipeline, and the one was placed in the air only section of the tube. There were also 30 pairs of pressure detectors that measure the pressure difference between two close points to evaluate the pressure gradient at the middle of those two points. Before

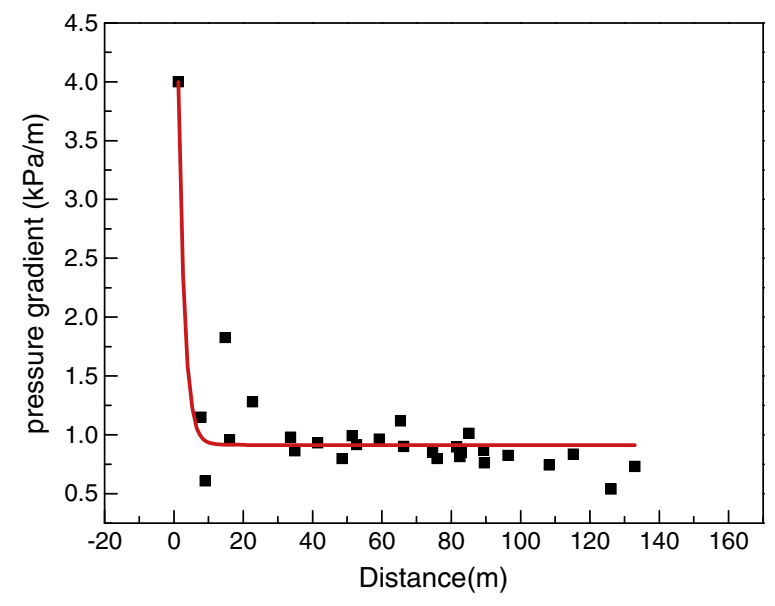

Fig. 7. The pressure gradients along the conveying distance. 
constructing Fig. 7, all bends and vertical sections were numerically transformed to be a 'horizontal' section by accounting their equivalent distance.

It can be seen that the pressure gradient dramatically decreases from $4 \mathrm{kPa} / \mathrm{m}$ to $0.7 \mathrm{kPa} / \mathrm{m}$ in a very short distance, around $10 \mathrm{~m}$ after the conveying inlet, and then it becomes stable at $0.7 \mathrm{kPa} / \mathrm{m}$ along the remaining distance. The results indicate that the whole conveying distance can be divided into two parts. One is a developing part, in which the pressure gradient decreases sharply. Another one is a fully developed part, in which the pressure gradient is almost stable. Based on this observation, as previously noted, the developing and the developed sections were calculated separately in CFD simulations.

Fig. 8(a) shows how the solids flow rate changes with gas volumetric flow rate. The solids flow rate firstly increases and then decreases with increasing gas volume flow rate. The peak value appears at approximately $550 \mathrm{Nm}^{3} / \mathrm{h}$ of the gas volumetric flow rate for all the conveying pressures. Furthermore, from the figure it can be seen that as the conveying pressure increases the solids flow rate increases. The results suggest that the increase of air flow rate does not always result in the increase of the solids flow rate. The increase of the air flow rate will induce the change of the conveying pattern from dense phase conveying to dilute phase conveying. In the latter case, particles are suspending in the air and follow the air. In this situation the individual particles move at a higher velocity but the mean particle number density is greatly reduced, therefore the total solids flow rate decreases.

Fig. 8(b) also shows that an increase in conveying pressure results in a decrease of the unit conveying power consumption. From both Fig. 8 (a) and (b), it can be concluded that higher pressure and lower air flow rate can help to reduce the power consumption (at a given solids flow rate). Under high pressure and low air flow rate, particles will move as a

\section{(a)The solids flow rate vs. the air volumetric flow rate}

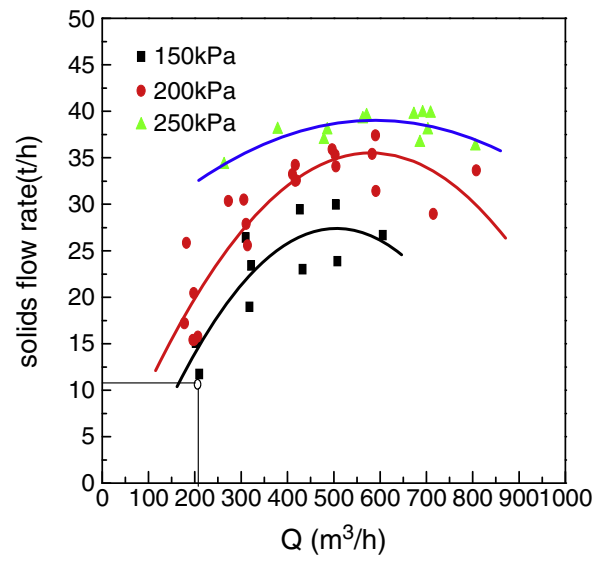

(b) Unit power consumptions vs. air volumetric flow rate

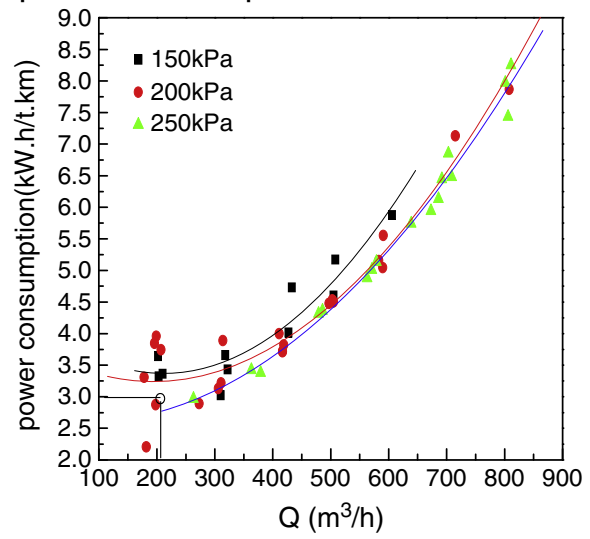

Fig. 8. The solid loading rates and unit p consumptions vs. the air volume flow rate. 'pile'. In this situation, the motive force for conveying is predominately made up by the pressure difference between the upstream and downstream sides of the material 'pile' to against the wall friction.

\subsection{Simulation}

This study numerically investigated the experimental cases based on the methodology introduced in Section 3. The air flow rate and power consumption for conveying $11.7 \mathrm{t} / \mathrm{h}$ particle are plotted in Fig. 8(a) and (b). It can be seen that the simulation results presented in are close to the experimental results. The predicted air volumetric flow rate is $210 \mathrm{~m}^{3} / \mathrm{h}$, which is the same as the experimental result under air pressure $150 \mathrm{kPa}$. The predicted lowest energy power consumption is $3.0(\mathrm{~kW} \mathrm{~h}) /(\mathrm{t} \mathrm{km})$, while the tested power consumption is $3.36(\mathrm{~kW} \mathrm{~h}) /(\mathrm{t} \mathrm{km})$. It should be noted that in order to avoid pipeline blockage, according to the requirement from a conveying company, the case, in which the air flow rate is below $200 \mathrm{Nm}^{3} / \mathrm{h}$, is not considered as a candidate of the optimum case.

\section{Conclusion}

A new method based on the use of both experimental work and CFD simulation is proposed in this paper. It predicts the power consumption for DTS pneumatic conveying. The simulation results are in good agreement with experimental data. The increase of air volumetric rate does not always result in the increase of the solids flow rate in this system. It will induce the change of the conveying pattern from dense phase conveying to dilute phase conveying, and will result in an increase of the unit power consumption. Although higher pressure and lower air flow rate are expected to save conveying power, the air flow rate should be kept higher than a certain value in order to avoid pipeline blockage.

\section{Acknowledgements}

This research was supported by the National Natural Science Foundation of China (Grant No. 10972223), CAS Innovation Program, and the item of improvement of pneumatic conveying lab which was from State Grid Company.

\section{References}

[1] David Mills, Pneumatic Conveying Design Guide, Second EditionElsevier, 2004

[2] A. Lippert, Pneumatische Förderung bei hohen Gutkonzentrationen (Pneumatic conveying of high solid concentration), Chemie-Ing. Techn. 38 (3) (1966) 350-355.

[3] Huang Biao, Pneumatic Conveying, Shanghai Science and Technology Publisher, 1984.

[4] D. McGlinchey, A. Cowell, CFD visualisation of pneumatic conveying passive bypass line, Bulk Solids \& Powder Science \& Technology 3 (3) (2008) 109-115.

[5] D. McGlinchey, A. Cowell, E.A. Knight, J.R. Pugh, A. Mason, B. Foster, Bend pressure drop predicitons using the Euler-Euler Model in dense phase pneumatic conveying, Particulate Science and Technology 25 (6) (2007) 495-506 http://www. informaworld.com/smpp/title $\sim \mathrm{db}=$ all $\sim$ content $=\mathrm{t} 713774907 \sim \mathrm{tab}=\mathrm{issueslist} \sim$ branches $=25$.

[6] D. McGlinchey, A. Cowell, Varying parameters of the fluent Eulerian model for predicting pressure drops in pneumatic transport, International Congress on Particle Technology, Nuremberg, Germany, March 2007, pp. 27-29.

[7] Santiago Laín, Martin Sommerfeld, Euler/Lagrange computations of pneumatic conveying in a horizontal channel with different wall roughness, Powder Technology 184 (2008) 76-88.

[8] Muslikhin Hidayat, Anders Rasmuson, A computational investigation of nonisothermal gas-solid flow in a U-bend, Powder Technology 175 (2007) 104-114

[9] D. Geldart, Types of gas fluidisation, Powder Technology 7 (1973) 285-292.

[10] Yu. Zhang, Ling Chen, Chunxia Zhang, Lixin Yu, Xiaolin Wei, Lvao Ma, Chunsheng Guan, CFD analysis of pneumatic conveying in a double-tube-socket (DTS) pipe, Applied Mathematical Modelling 34 (2010) 3085-3097. 